\title{
A homolog of lariat-debranching enzyme modulates turnover of branched RNA
}

\author{
STEPHEN M. GARREY, ${ }^{1}$ ADAM KATOLIK, ${ }^{2}$ MANTAS PREKERIS, ${ }^{1}$ XUENI LI, ${ }^{1}$ KERRI YORK, ${ }^{1}$ SARAH BERNARDS, ${ }^{3}$ \\ STANLEY FIELDS, ${ }^{3,4,5}$ RUI ZHAO, ${ }^{1}$ MASAD J. DAMHA, ${ }^{2}$ and JAY R. HESSELBERTH ${ }^{1}$ \\ ${ }^{1}$ Department of Biochemistry and Molecular Genetics, University of Colorado School of Medicine, Aurora, Colorado 80045, USA \\ ${ }^{2}$ Department of Chemistry, McGill University, Montreal, Quebec H3A 2K6, Canada \\ ${ }^{3}$ Department of Genome Sciences, ${ }^{4}$ Howard Hughes Medical Institute, ${ }^{5}$ Department of Medicine, University of Washington, Seattle, \\ Washington 98195, USA
}

\begin{abstract}
Turnover of the branched RNA intermediates and products of pre-mRNA splicing is mediated by the lariat-debranching enzyme Dbr1. We characterized a homolog of Dbr1 from Saccharomyces cerevisiae, Drn1/Ygr093w, that has a pseudometallophosphodiesterase domain with primary sequence homology to Dbr1 but lacks essential active site residues found in Dbr1. Whereas loss of Dbr1 results in lariat-introns failing broadly to turnover, loss of Drn1 causes low levels of lariat-intron accumulation. Conserved residues in the Drn1 C-terminal CwfJ domains, which are not present in Dbr1, are required for efficient intron turnover. Drn1 interacts with Dbr1, components of the Nineteen Complex, U2 snRNA, branched intermediates, and products of splicing. Drn1 enhances debranching catalyzed by Dbr1 in vitro, but does so without significantly improving the affinity of Dbr1 for branched RNA. Splicing carried out in in vitro extracts in the absence of Drn1 results in an accumulation of branched splicing intermediates and products released from the spliceosome, likely due to less active debranching, as well as the promiscuous release of cleaved 5'-exon. Drn1 enhances Dbr1-mediated turnover of lariat-intermediates and lariat-intron products, indicating that branched RNA turnover is regulated at multiple steps during splicing.
\end{abstract}

Keywords: Dbr1; branched RNA; splicing; Nineteen Complex

\section{INTRODUCTION}

Pre-mRNA splicing by the spliceosome is carried out in two successive catalytic steps. In the first step, the $2^{\prime}$-hydroxyl of an internal adenosine residue (the "branch point") attacks the phosphodiester upstream of the $5^{\prime}$-splice site, yielding a cleaved $5^{\prime}$-exon and a lariat-exon intermediate. In the second step, the $3^{\prime}$-hydroxyl of the $5^{\prime}$-exon attacks the phosphodiester at the $3^{\prime}$-splice site, ligating the exons and creating a lariat-intron product. The ligated exons are released for subsequent translation, while the lariat-intermediate (from unproductive splicing) and lariat-intron (upon splicing completion) are released for degradation.

Branched RNA as found in lariat structures created during splicing is debranched to linear form for exonucleolytic decay by the lariat-debranching enzyme Dbr1. If the second step of splicing is unproductive, the resulting lariat-intermediates are discarded by the DEAH-box ATPase Prp43 (Mayas et al. 2010), linearized by Dbr1-mediated debranching (Khalid et al. 2005), and further degraded by the cytoplasmic exosome (Hilleren and Parker 2003). If splicing is productive,

Corresponding author: jay.hesselberth@ucdenver.edu

Article published online ahead of print. Article and publication date are at http://www.rnajournal.org/cgi/doi/10.1261/rna.044602.114. lariat-intron complexes are disassembled by Prp43 and the Ntr1 cofactor (Martin et al. 2002; Tanaka et al. 2007; Tsai et al. 2007; Fourmann et al. 2013). These complexes contain the U2, U5, and U6 snRNAs, as well as members of the Nineteen Complex (Yoshimoto et al. 2009; Fourmann et al. 2013). Debranching of lariat-introns by Dbr1 requires their release from post-splicing complexes by the DEAH-box ATPase Prp43 and accessory Ntr1 and Ntr2 factors (Martin et al. 2002; Fourmann et al. 2013).

Despite the activity of the debranching pathway, a number of lariat-intermediates and lariat-introns are stable in cells (Hesselberth 2013). Furthermore, turnover efficiency among branched RNA products is variable. For example, lariat-introns with branch site A-to-C mutations are poor substrates for the lariat-debranching enzyme (Jacquier and Rosbash 1986). This enzyme also prefers substrates with a purine at the $2^{\prime}$-position (Nam et al. 1994). These results suggest that products of incorrect $5^{\prime}$-splice site selection (i.e., the future $2^{\prime}$-position in the lariat-intron) are poor substrates for

(c) 2014 Garrey et al. This article is distributed exclusively by the RNA Society for the first 12 months after the full-issue publication date (see http:// rnajournal.cshlp.org/site/misc/terms.xhtml). After 12 months, it is available under a Creative Commons License (Attribution-NonCommercial 4.0 International), as described at http://creativecommons.org/licenses/by-nc/4.0/. 
debranching in vivo. Pre-mRNAs with a branch site A-to-G mutation complete the first step of splicing but strongly inhibit the second step (Liu et al. 2007), producing high levels of lariat-intermediates that are exported to the cytoplasm and can be translated (Mayas et al. 2010). Debranching of these lariat-intermediates by Dbr1 comprises a quality control mechanism for lariat-intermediates that do not complete splicing and escape into the cytoplasm (Hilleren and Parker 2003). Shuttling of human Dbr1 between the nucleus and cytoplasm is dynamic (Kataoka et al. 2013), and phosphorylated forms of both Dbr1 and Drn1 have been detected by proteomic analysis (Stark et al. 2010), suggesting that RNA turnover by debranching is subject to regulation by both localization and post-translational modification.

We characterized a novel splicing factor, Drn1/Ygr093w, in Saccharomyces cerevisiae that modulates the turnover of branched RNAs by Dbr1. We show that Drn1 acts in concert with Dbr1 to promote the turnover of lariat-intermediates and lariat-intron RNAs produced during and after the catalytic steps of splicing.

\section{RESULTS}

\section{Drn1/Ygr093w is a homolog of the lariat-debranching enzyme Dbr1}

S. cerevisiae Drn1 is a nonessential protein with two annotated C-terminal CwfJ ("complexed with five") domains (Ohi et al. 2002). By use of profile-hidden Markov model-based searches (Finn et al. 2011), we identified a large region of homology between the $\mathrm{N}$ terminus of Drn 1 and the N-terminal metallophosphodiesterase domain of Dbr1, a calcineurin-like $2^{\prime}-5^{\prime}$ phosphodiesterase (Fig. 1A; Khalid et al. 2005). However, despite the homology between these domains of Drn1 and Dbr1, nearly all of the residues essential for Dbrl catalytic activity (e.g., His 13, 86, 179, 231, and 233; Asp 180; Glu 87) (Khalid et al. 2005) are found as nonconservative mutations in Drn1 orthologs (Fig. 1B, red arrows), suggesting that this domain does not catalyze RNA debranching.

Drn1 is evolutionarily conserved from S. cerevisiae to humans with identical domain organization (Fig. 1B). The Cterminal CwfJ domains of Drn1 contain a series of evolutionarily conserved cysteine and histidine residues (Cys 269 and 272; His 311, 319, 366, and 368) (Fig. 1C, purple arrows), with an arrangement similar to the $\mathrm{CCCH}$-class of zinc fingers (Ruby et al. 2007; Finn et al. 2009), suggesting that these residues in the Drn1 CwfJ domains may comprise a metal binding site. Paralogs of Drn1 in Schizosaccharomyces pombe (cwf19) and humans (CWF19L2) have C-terminal CwfJ domains but lack N-terminal Dbrl homology.

\section{Drn1 interacts with spliceosomal components and branched RNA products of splicing}

There are evolutionarily conserved interactions between Drn 1 and spliceosomal components. A previous study identified an interaction between S. cerevisiae Drn1 and the Nineteen Complex component Ntc40/Cwc2 (Hazbun et al. 2003); paralogs of Drn1 in S. pombe (Cwf19p and Mug161p) copurify with Nineteen Complex components (Ohi et al. 2002; Ren et al. 2011; Chen et al. 2014); and human Drn1 paralogs (Cwf1911 and Cwf1912) copurify with spliceosomes (Rappsilber et al. 2002).

We used the yeast two-hybrid assay to identify protein interactions between Drn1 and Dbr1 and also identified an interaction between Drn1 and the Nineteen Complex component Ntc90/Syf1 in an unbiased screen for Drn1 interactors (Fig. 2A). We observed weaker and orientation-dependent two-hybrid signals between Drn1 and Ntc30/Isy1 and between Dbr1 and Ntc30/Isy1, an interaction partner of
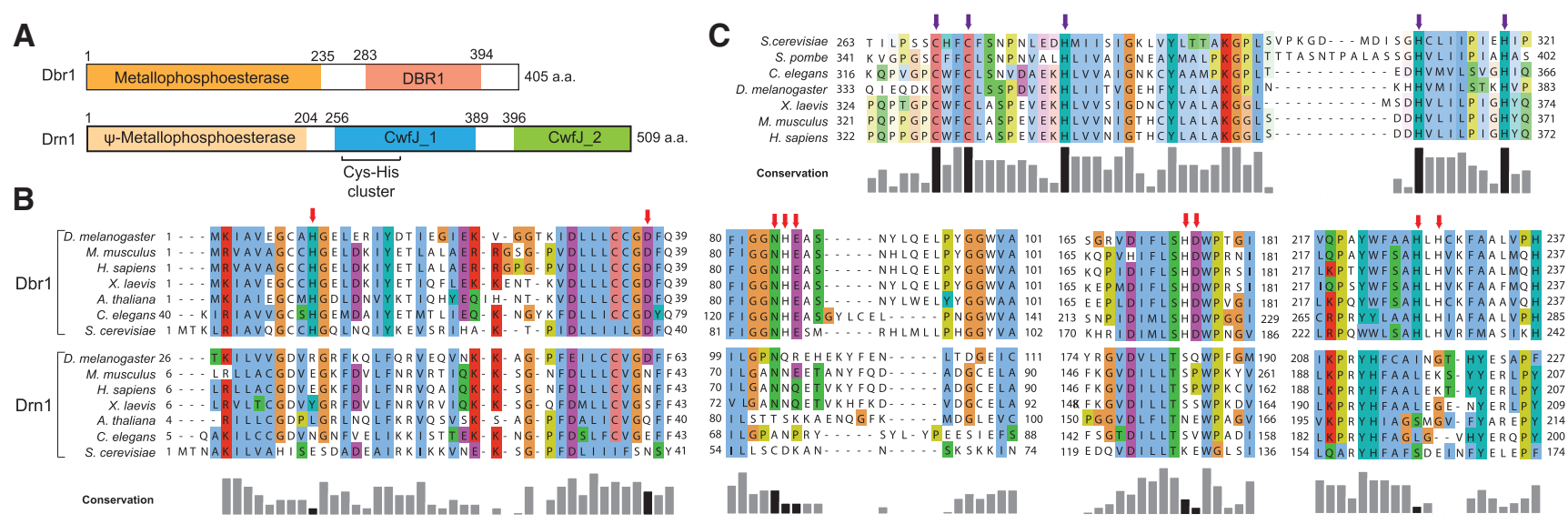

FIGURE 1. Drn1 is a homolog of the lariat-debranching enzyme Dbr1. (A) Protein domains in Drn1 and Dbrl. The pseudo-metallophosphoesterase domain in Drn1 is homologous to the metallophosphoesterase domain of Dbr1. (B) Multiple sequence alignment showing N-terminal homology between the metallophosphoesterase regions of Dbr1 and Drn1. Essential catalytic residues in Dbr1 (Khalid et al. 2005) are marked with red arrows (note regions are discontinuous). (C) Multiple sequence alignment of a portion of the Drn1 Cwf__1 domain showing evolutionary conservation of a series of Cys and His residues (purple arrows). 

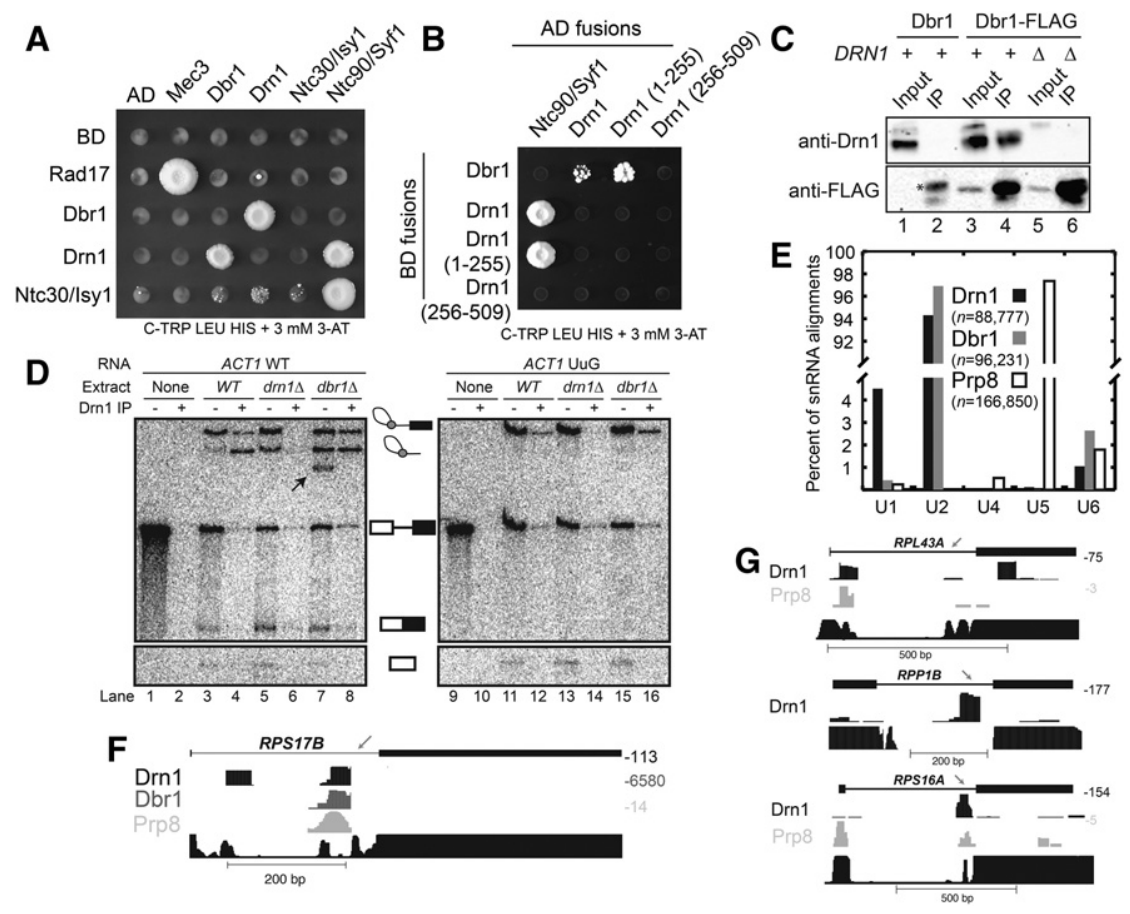

FIGURE 2. Drn1 interacts with Dbr1, components of the Nineteen Complex, U2 snRNA, and branched intermediates and products of pre-mRNA splicing. (A) Yeast two-hybrid analysis of Drn1 interactions. Proteins were tested as Gal4 activation (AD) and binding (BD) domain fusions on selective media. Mec3/Rad17 is a positive control, and Drn1 and Dbr 1 interact as reciprocal AD/ BD fusions. Drn1 interacts with Ntc90; the Ntc90-Ntc30 (Syf1-Isy1) interaction was reported previously (Dix et al. 1999). (B) Yeast two-hybrid analysis of Drn1 domain interactions. The Drn1 Nterminal domain (residues 1-255) and C-terminal domain (256-509) were tested as Gal4-AD and BD fusions against Dbr1-BD and Ntc90/Syf1-AD fusions. Strong interactions were observed between Drn1, Drn1-1-255, and Ntc90/Syf1, and weaker interactions we observed with Drn1, Drn1-1-255, and Dbr1. (C) Drn1 and Dbr1 interact in splicing extracts. Splicing extracts were prepared from wild-type (WT; lanes 1,2), Dbr1-Flag (lanes 3,4), and Dbr1-Flag drn1 1 (lanes 5,6) yeast strains. Inputs $(5 \%$; lanes $1,3,5)$ and anti-Flag immunoprecipitations (lanes $2,4,6$ ) were analyzed by Western blotting with anti-Drn1 antibodies (top) and anti-Flag antibodies (bottom). Drn1 is specifically isolated in the Dbr1-Flag splicing extracts (lane 4). A nonspecific protein isolated by anti-Flag antibodies is marked with an asterisk. $(D)$ Copurification of Drn 1 and branched RNA intermediates. Anti-Drn 1 antibodies were used to immunoprecipitate Drn 1 from in vitro splicing reactions with WT, $d r n 1 \Delta$, and $d b r 1 \Delta$ extracts. IP - indicates $10 \%$ input; IP + indicates RNA recovered by immunoprecipitation with anti-Drn 1 antibodies of remaining $90 \%$. WT ACT1 premRNA and a 3 '-splice site mutant (UAG-to-UuG) were used in the assays. A black arrow indicates a faster-migrating RNA species likely derived from processing of lariat-intermediate or lariat-intron. (E) Summary of snRNA interactions observed in Drn1, Dbr1, and Prp8CLIP-seq experiments (read numbers indicated in the legend; $y$-axis is discontinuous). Prp8 is crosslinked mainly to U5 snRNA, whereas Dbr 1 and Drn 1 crosslink to U2 snRNA. (F) CLIP-seq signals in the RPS17B intron. Sequencing coverage (i.e., reads per base) is indicated to the right of each track. Conservation among six sensu stricto yeast strains (Siepel et al. 2005) is indicated at the bottom in black. The peak of conservation indicated by the gray arrow is the branch site. Drn 1, Dbr1, and Prp8 (Li et al. 2013) crosslink near the branch point sequence; Drn1 also crosslinks downstream from the $5^{\prime}$-splice site. $(G)$ Drn1 and Prp8 CLIP-seq signals over the RPL43A, RPP1B, and RPS16A pre-mRNAs; annotations are as in F. No Dbrl CLIP-seq signals were observed for any of these pre-mRNAs.

Ntc90/Syf1 (Fig. 2A; Dix et al. 1999). We further analyzed these interactions by assaying the Drn $1 \mathrm{~N}$ terminus (residues 1-255) and C terminus (residues 256-509) as activation domain fusions and found that the $\mathrm{N}$ terminus of Drn1 is sufficient to interact with both Ntc90/Syf1 and Dbr1 (Fig. 2B).

We also tested whether Dbr1 and Drn1 associate in splicing extracts. We immunoprecipitated Drn1 and Dbr1 from splicing extracts and analyzed associated proteins by Western blot. We found that Drn1 and Dbr1 associated in the extracts (Fig. 2C), corroborating a previous affinity purification that identified an interaction between Drn1 and Dbr1 (Gavin et al. 2006).

Dbr1 debranches lariat-introns (Khalid et al. 2005) and lariat-intermediates (Hilleren and Parker 2003), and thus we tested whether Drn1 associates with these branched RNAs. We affinity purified Drn 1 from in vitro splicing reactions and identified coprecipitating splicing intermediates from either a wild-type (WT) $A C T 1$ pre-mRNA substrate, or an ACT1 pre-mRNA with a $3^{\prime}$ splice site mutation (UAG-to-UuG), which stalls splicing prior to the second catalytic step (Fig. 2D; Mayas et al. 2006). Drn1 immunoprecipitated lariat-intermediate and lariat-intron products spliced from WT premRNA (Fig. 2D, cf. lanes 3 and 4); this interaction was absent in drn1 $1 \Delta$ extracts (Fig. 2D, lane 6). Drn1 immunoprecipitated lariat-intron more efficiently than lariat-intermediate, suggesting that Drn1 is mainly associated with post-catalytic complexes containing lariat-intron. In $d b r 1 \Delta$ extracts, we observed modest stabilization of branched RNAs (cf. lanes 7 and 3), and Drn1 immunoprecipitated both lariat-intron and lariat-intermediate. We also observed a faster migrating intron species consistent with a lariat-intron lacking its tail (Fig. 2D, lane 7, black arrow) and found that Drn1 did not immunoprecipitate this RNA (Fig. 2D, cf. lanes 7 and 8). Drn 1 immunoprecipitated lariat-intermediates derived from premRNAs with a $3^{\prime}$-splice site mutation (Fig. 2D), and this interaction was not detected in a $d r n 1 \Delta$ extract (Fig. 2D, lane 14). These studies show that Drn1 interacts either directly or indirectly with both lariat-intermediate and lariat-intron, suggesting it has a role in the release or turnover of these molecules.

We examined the global association of TAP-tagged Drn 1 and Dbr1 to RNA in vivo by CLIP-seq (Fig. 2E-G; Zhang and Darnell 2011). Over 30\% of the reads from these libraries mapped to the sequences for the U1, U2, U4, U5, and U6 snRNAs, and of these, Drn1-TAP and Dbr1-TAP crosslinked predominantly with U2 snRNA ( $94 \%$ of reads for Drn1-TAP; 97\% for Dbr1-TAP) (Fig. 2E). Insofar as U2 snRNA base-pairs with the branch site adenosine and is present in post-catalytic complexes containing lariat-intron 
(Yoshimoto et al. 2009; Fourmann et al. 2013), these interactions are consistent with a role for both Dbr1 and Drn1 in branched RNA metabolism. Previously, we used CLIP-seq to show that Prp8-TAP crosslinked predominantly to U5 snRNA (98\% of all sequencing reads that mapped to snRNAs) (Fig. 2E), consistent with the role of $\operatorname{Prp} 8$ as a core U5 snRNP component (Grainger and Beggs 2005; Li et al. 2013).

We also examined Drn1 and Dbr1 CLIP-seq signals in premRNAs (Fig. 2F,G). Overall, $\sim 1 \%$ of the sequencing reads (about 10,000 reads from each library) mapped to premRNA regions. Surprisingly, the $R P S 17 B$ intron was the only intron that robustly crosslinked to both Drn1 and Dbr1, with CLIP peaks near the branch site of the intron (Fig. 2F). However, significantly fewer reads were found in the RPS17B exons, suggesting that Drn1 and Dbr1 interact with the RPS $17 B$ intron after splicing. Of the remaining CLIP signals, Drn1 interacted with far more introns than Dbr1. Overall, we identified 68 introns with significant Drn1 CLIP-seq peaks; RPS17B was the single intron with significant association with Dbr1. Of the Drn1 CLIP-seq peaks, many were clustered near the branch point of the intron $(R P P 1 B$ and RPS16A) (Fig. 2G). In addition, some pre-mRNAs exhibited more distributed Drn1 CLIP-seq signals (e.g., RPL43A, which accumulates in the absence of Drn1) (Fig. 3A), with signals in both the introns and second exon, consistent with interactions between Drn 1 and $5^{\prime}$-exons, lariat-intermediates, or unspliced pre-mRNAs (Fig. 2G).

\section{Cells lacking Drn1 accumulate pre-mRNA splicing intermediates}

We used tiling microarrays (Hiley et al. 2005) to analyze the steady-state abundance of about 400 coding and noncoding RNAs in WT and drn1s strains. This experiment identified splicing intermediates from several ribosomal protein pre-mRNAs that accumulate in the absence of Drn1. PremRNAs encoding small (RPS18A, RPS21B) and large ( $R P L 43 A)$ ribosomal subunit proteins exhibited increased signals in intronic regions. We validated several of these candidates by Northern blotting with probes to specific premRNA regions (Fig. 3A). DRN1 deletion caused the accumulation of RPS18A lariat-intron by Northern blot, validating the tiling microarray results. In addition, we observed similar

A
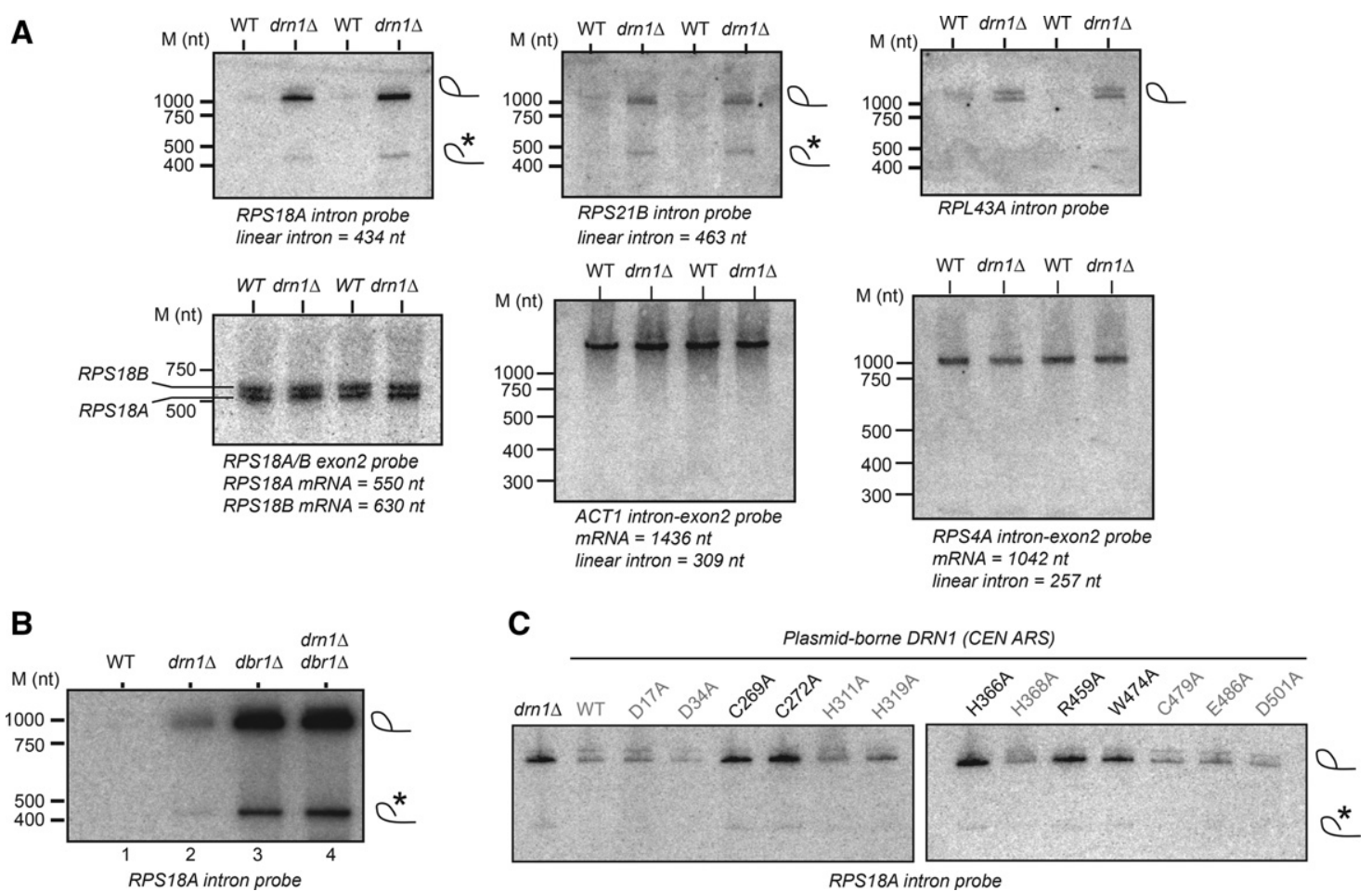

FIGURE 3. Loss of Drn 1 causes accumulation of pre-mRNA splicing intermediates and products in vivo. (A) Pre-mRNA intermediate accumulation was measured by acrylamide Northern blot. Predicted positions of lariat-intron are indicated in the top panels. The indicated probes are specific for intron, exon2, or intron-exon2 junctions. A band comigrating with linear intron is marked with an asterisk, consistent with nicked lariat-intron. Sizes were estimated by staining of an RNA molecular weight standard excised prior to blotting. (B) Northern blot for RPS18A intron in cells lacking combinations of DRN1 and DBR1. Loss of $d r n 1 \triangle$ causes mild accumulation of RPS18A lariat-intron, whereas $d b r 1 \triangle$ causes high levels of RPS18A lariatintron accumulation independent of $D R N 1$. A presumed nicked lariat-intron is marked with an asterisk. $(C)$ Complementation of $R P S 18 A$ intron accumulation in $d r n 1 \Delta$ cells by plasmid-encoded $D R N 1$ variants. WT DRN1 rescues the intron accumulation phenotype of $d r n 1 \Delta$. Alanine substitutions in the N-terminal Dbr1 domain (D17A, D43A) fail to disrupt Drn1 activity, whereas alanine substitutions at conserved positions in the CwfJ domains (C269A, C272A, H366A, R459A, W747A, black) are unable to complement RPS18A intron accumulation caused by $d r n 1 \Delta$. 
accumulations of lariat-introns for the RPS21B and RPL43A introns in $d r n 1 \Delta$ cells (Fig. 3A). In contrast to the detection of these lariat-intron products, probes specific to the RPS18A/B exons identified bands migrating at the expected positions of spliced RPS18A and RPS18B mRNAs, with no apparent change in their steady-state abundance in the absence of Drn 1 . We also examined pre-mRNAs that did not have detectable intronic hybridization on the tiling microarray. Probes spanning the ACT1 and RPS4A pre-mRNA intron-exon junctions identified single bands that migrated at the size of their spliced mRNAs but lacked detectable hybridization to intron-containing isoforms (e.g., pre-mRNA, lariat-intermediate and lariat-intron), validating the microarray results.

To assess the relative contributions of Drn1 and Dbr1 during debranching in vivo, we examined the accumulation of the RPS18A lariat-intron in strains lacking combinations of $D R N 1$ and DBR1 (Fig. 3B). We found that the mild lariat-intron accumulation phenotype in $d r n 1 \Delta$ strains was much more pronounced in $d b r 1 \Delta$ strains, and the double $d r n 1 \Delta$ $d b r 1 \Delta$ deletion strain exhibited accumulation equivalent to $d b r 1 \Delta$ alone, suggesting that $\operatorname{Dbr} 1$ is required for the majority of RPS18A lariat-intron turnover.

We tested whether evolutionarily conserved residues in the Drn1 CwfJ domains (Fig. 1C) are required for intron metabolism in vivo. We complemented a $d r n 1 \Delta$ strain with singlecopy CEN-ARS plasmids expressing either WT DRN1 or with DRN1 mutants containing alanine substitutions at conserved positions (Fig. 3C; Alberti et al. 2007). We selected several residues based on their conservation among DRN1 orthologs (e. g., Cys 269, Cys 272, and His 366 in the C-terminal CwfJ domains) (Fig. 1C) and their similarity to residues of the metallphosphoesterase domain of Dbr1 (Asp 17 and Asp 34) (Fig. 1B). We analyzed RNA from these strains by Northern blot using a probe for the RPS18A lariat-intron, which accumulates in $d r n 1 \Delta$ strains (Fig. 3A). This analysis showed that several residues (Cys 269 and 272, His 361, Arg 459, and Trp 474) in the C-terminal CwfJ domains are required for turnover of the RPS18A intron in vivo, whereas $\mathrm{N}$-terminal residues conserved in Dbr1 (Asp 17 and Asp 34) are not required for Drn1 function. These data implicate key residues in the C-terminal CwfJ domains that mediate Drn1 function in vivo.

\section{Drn1 enhances Dbr1 catalytic activity in vitro}

Given the homology between Drn1 and Dbr1 (Fig. 1) and their physical and functional associations (Fig. 2), we reasoned that Drn1 might affect the RNA binding and debranching activity of Dbr1. We used a 7-nucleotide (nt) branched RNA (Fig. 4A) to measure the affinity of Dbr1 for branched RNA. We expressed and purified Dbr1, Dbr1-H86A, and Drn1 from Escherichia coli (Fig. 2B) and used them in binding and activity assays. The mutant Dbr1 protein (His 86 to Ala; H86A) binds to branched substrates (Fig. 4D) but lacks detectable debranching activity (Khalid et al. 2005). We measured the affinity of Dbr1-H86A for the 7-nt synthetic branched RNA in a filter-binding assay to determine a $\mathrm{K}_{\mathrm{D}}$ of $507 \mathrm{nM}$ for the Dbr1-H86A:RNA complex; Dbr1-H86A did not bind a short linear RNA in the same assay (data not shown). Addition of $4 \mu \mathrm{M}$ Drn1 to the binding reactions modestly improved the affinity of Dbr1 for RNA $\left(K_{\mathrm{D}}=379\right.$ nM) (Fig. 4D), but $4 \mu \mathrm{M}$ Drn1 alone did not bind the branched substrate (data not shown).

We varied the concentration of Dbr1 in cleavage assays to assess its ability to debranch the 7-nt branched RNA substrate and found that Dbr1 achieved 50\% conversion of the branched substrate in $30 \mathrm{~min}$ at a concentration of $50 \mathrm{nM}$ (Fig. 4C,E). Addition of $0.5 \mu \mathrm{M}$ Drn 1 to these assays enhanced Dbr1-mediated turnover, reducing the amount of Dbr1 needed for $50 \%$ conversion to $\sim 5 \mathrm{nM}$, representing a 10 -fold improvement in apparent rate of debranching. Drn1 alone was unable to debranch the 7-nt substrate (at Drn1 concentrations up to $5 \mu \mathrm{M}$ ) (Fig. $4 \mathrm{~F}$ ), suggesting that it interacts with Dbrl to enhance branched RNA turnover. In a previous study (Khalid et al. 2005), Dbr1 was about fivefold more active in debranching assays. Our substrate was $7 \mathrm{nt}$ in size, whereas the previous study used substrates between 18 and $29 \mathrm{nt}$; it is possible that Dbr1 binds larger substrates with higher affinity, accounting for the higher rate of debranching in the previous study.

We also asked how Drn1 affects the kinetics of Dbr1-mediated debranching. At a high concentration $(25 \mathrm{nM})$, Dbr1 converted $50 \%$ of the 7 -nt branched substrate to linear form in $60 \mathrm{sec}$ (Fig. 4F,G). Addition of $0.5 \mu \mathrm{M}$ Drn1 greatly accelerated Dbrl-mediated debranching, with $80 \%$ of the substrate converting to linear form in $60 \mathrm{sec}$; this concentration of Drn1 alone was unable to debranch the RNA substrate (Fig. $4 \mathrm{~F}$ ). We observed $\sim 5 \%$ debranching after 30 min at a lower concentration of Dbr1 (6.25 nM) (Fig. 4H,I). However, addition of $0.5 \mu \mathrm{M}$ Drn1 to these reactions enhanced debranching of the substrate by Dbr1, achieving $50 \%$ conversion in $5 \mathrm{~min}$.

\section{Drn1 modulates turnover of branched RNA during splicing in vitro}

We analyzed the function of Drn1 with splicing extracts (Stevens and Abelson 2002; Mayas et al. 2006) prepared from WT, $d r n 1 \Delta$, and $d b r 1 \Delta$ strains. These extracts were used to splice WT ACT1 pre-mRNA and a pre-mRNA with a $3^{\prime}$-splice site mutation (UAG to UuG). We examined the release of splicing intermediates and products in these reactions by glycerol gradient sedimentation (Fig. 5; Stevens and Abelson 2002). In the WT extract, WT ACT1 pre-mRNA was efficiently converted to mature mRNA and released into lighter fractions (Fig. 5A). In the dbr1 $\Delta$ extract, WT ACT1 pre-mRNA splicing resulted in the expected appearance of lariat-intron and lariat-intermediate in light fractions (Martin et al. 2002), as well as a faster migrating RNA (i.e., a lariat without a tail) sometimes seen during in vitro splicing (Fig. 5B; Krämer and Keller 1985; Arenas and Hurwitz 1987). In the $d r n 1 \Delta$ extract, WT ACT1 pre-mRNA splicing 


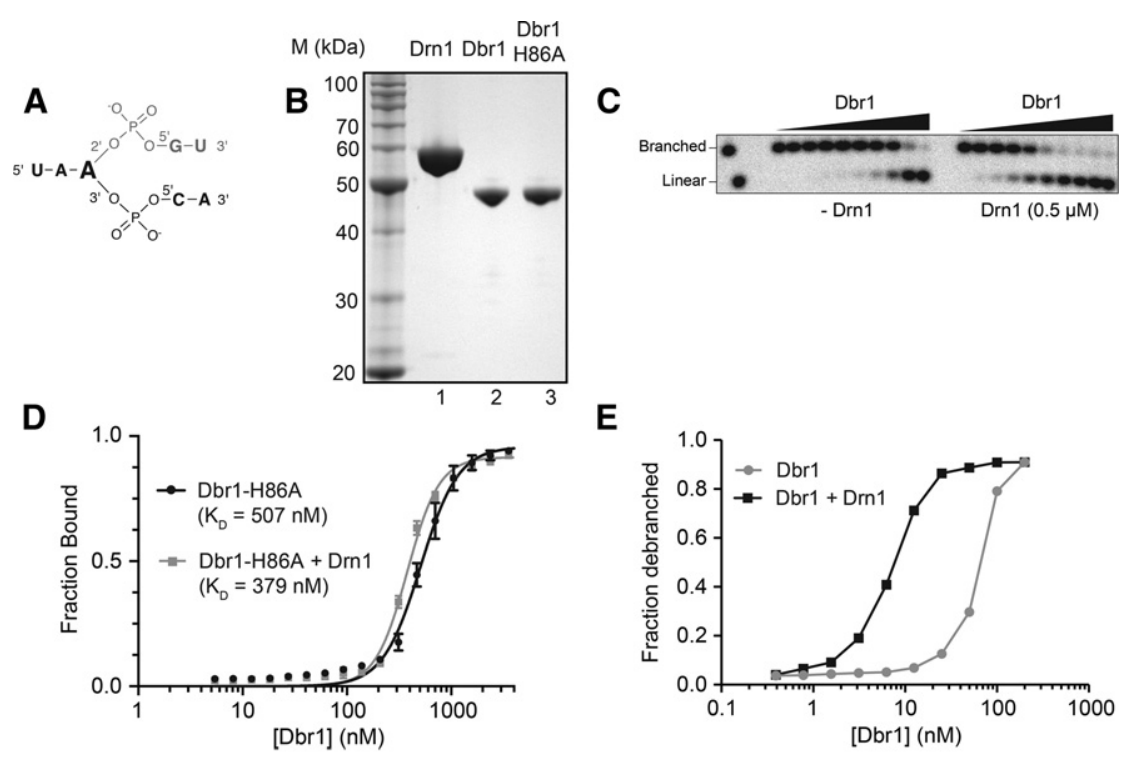

\section{$\mathbf{F}$}
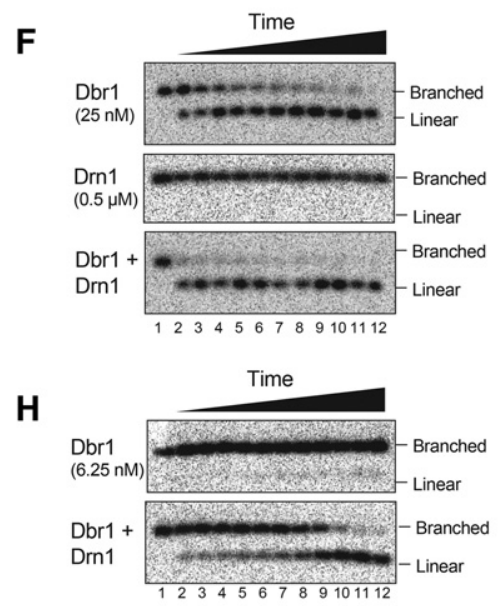

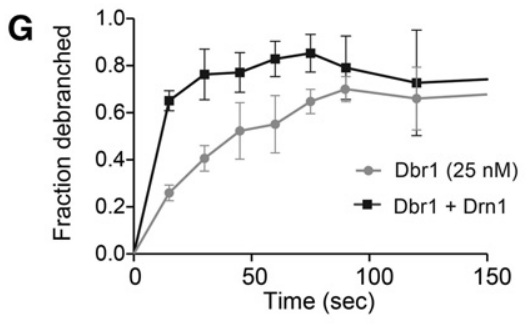

I

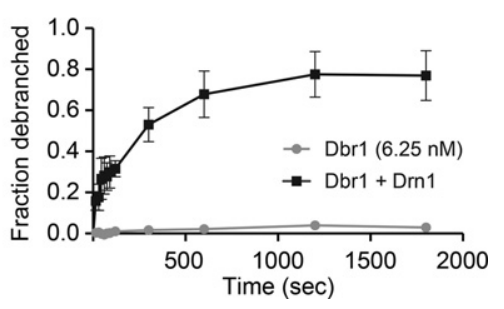

FIGURE 4. Drn1 enhances Dbrl debranching activity in vitro. (A) Structure of the 7-nt branched RNA substrate used in debranching assays. The 5-nt linear product of debranching is in black. (B) Coomassie-stained SDS-PAGE gel of purified recombinant Drn1 (lane 1), Dbr1 (lane 2), and Dbr1-H86A (lane 3). (C) Increasing amounts of Dbr1 (0, 0.4, 0.8, 1.6, 3.1, 6.3, $12.5,25,50,100$, and $200 \mathrm{nM}$ ) were incubated with $1 \mathrm{nM}{ }^{32} \mathrm{P}$-end-labeled substrate for 30 min at $22^{\circ} \mathrm{C}$ in the presence (right) or absence (left) of $0.5 \mu \mathrm{M}$ Drn 1 and analyzed by acrylamide gel electrophoresis. (Lanes 1,2) Standards for the branched and linear substrates. $(D)$ Binding isotherms for complexes of Dbr1-H86A and a 7-nt branched RNA substrate were determined by filter binding in the absence of Drn 1 (black; $K_{\mathrm{D}}=507 \mathrm{nM}$ ) and in the presence of $4 \mu \mathrm{M}$ Drn 1 (gray; $K_{\mathrm{D}}=379 \mathrm{nM}$ ). Error bars, SD of three independent experiments. (E) Quantitation of RNA debranching shown in $C$. $(F)$ Time course of RNA debranching. End-labeled substrate (1 nM) was incubated at $22^{\circ} \mathrm{C}$ in the presence of $25 \mathrm{nM}$ Dbrl (top), $0.5 \mu \mathrm{M}$ Drn1 (middle), or $25 \mathrm{nM}$ Dbr1 and $0.5 \mu \mathrm{M}$ Drn1 (bottom). Aliquots were removed at 15, 30, 45, 60, 75, 90, 120, 300, 600,1200 , and $1800 \mathrm{sec}$ and analyzed by denaturing acrylamide gel electrophoresis. $(G)$ Quantitation of cleavage shown in top and bottom panels of $F$; error bars, SD for three independent assays. $(H)$ Time course of RNA debranching. End-labeled substrate $(1 \mathrm{nM})$ was incubated in the presence of $6.25 \mathrm{nM}$ Dbr1 (top) or $6.25 \mathrm{nM}$ Dbr1 and $0.5 \mu \mathrm{M} \mathrm{Drn1}$ (bottom). Aliquots were removed at time points as in $F$ and analyzed by denaturing acrylamide gel electrophoresis. $(I)$ Quantitation of cleavage shown in $H$; error bars, SD for three independent assays.

resulted in the appearance of lariat-intermediate, lariat-intron, and a small amount of released $5^{\prime}$-exon in light fractions (Fig. 5C, bottom panel, frac. 4-10). In addition, whereas most of the branched RNAs released in the $d b r 1 \Delta$ extract were in the faster migrating intron form, branched RNAs released in the $d r n 1 \Delta$ extract were mainly in lariat-intron form, suggesting that Drn1 function is required for efficient production of the faster migrating intron form. Although we were unable to complement these extracts with recombinant Drn1 (data not shown), we observed identical release phenotypes in independent preparations of $d r n 1 \Delta$ splicing extract.

Pre-mRNA substrates with mutant $3^{\prime}$ splice sites impede exon ligation (Mayas et al. 2006). Splicing of ACT1 premRNA with a $3^{\prime}$ splice site UuG mutation in the WT extract resulted in efficient production of first-step products but significantly lower levels of second-step lariat-intron and mRNA products (Fig. 5D). In the $d b r 1 \Delta$ extract, the second step of splicing was inefficient, and lariat-intermediate was released into lighter fractions (Fig. 5E, top panel, fractions 8-10). The faster-migrating intron product was present in light fractions (fractions 4-10), but lariat-intron was not, suggesting that this faster migrating RNA is generated either from released lariat-intermediates or from spliceosome-bound lariat-introns (fractions 20-24). In assays with $d r n 1 \Delta$ extract and the UuG pre-mRNA, we observed release of $5^{\prime}$-exon, lariat-intron (Fig. 5F, fractions 4-6), and lariat-intermediate (fraction 10), similar to the release of these intermediates observed during splicing of WT pre-mRNA in $d r n 1 \Delta$ splicing extract (Fig. 5C).

\section{DISCUSSION}

We showed that Drn1 functionally interacts with Dbrl during pre-mRNA splicing to modulate the turnover of lariatintrons. In CLIP-seq experiments, Drn1 and Dbr1 directly interact with branched RNA, as well as the U2 snRNA (Fig. 2E,F). Moreover, Drn1 interacts with a larger number of introns than Dbr1, perhaps reflecting aspects of the interactions among Drn1, Dbr1, and branched RNA. More specifically, the Dbr1 enzyme might interact transiently with branched RNA substrates, precluding robust detection by crosslinking. In contrast, Drn1 interacts with lariat-intermediates and lariat-introns (Fig. 2D), 

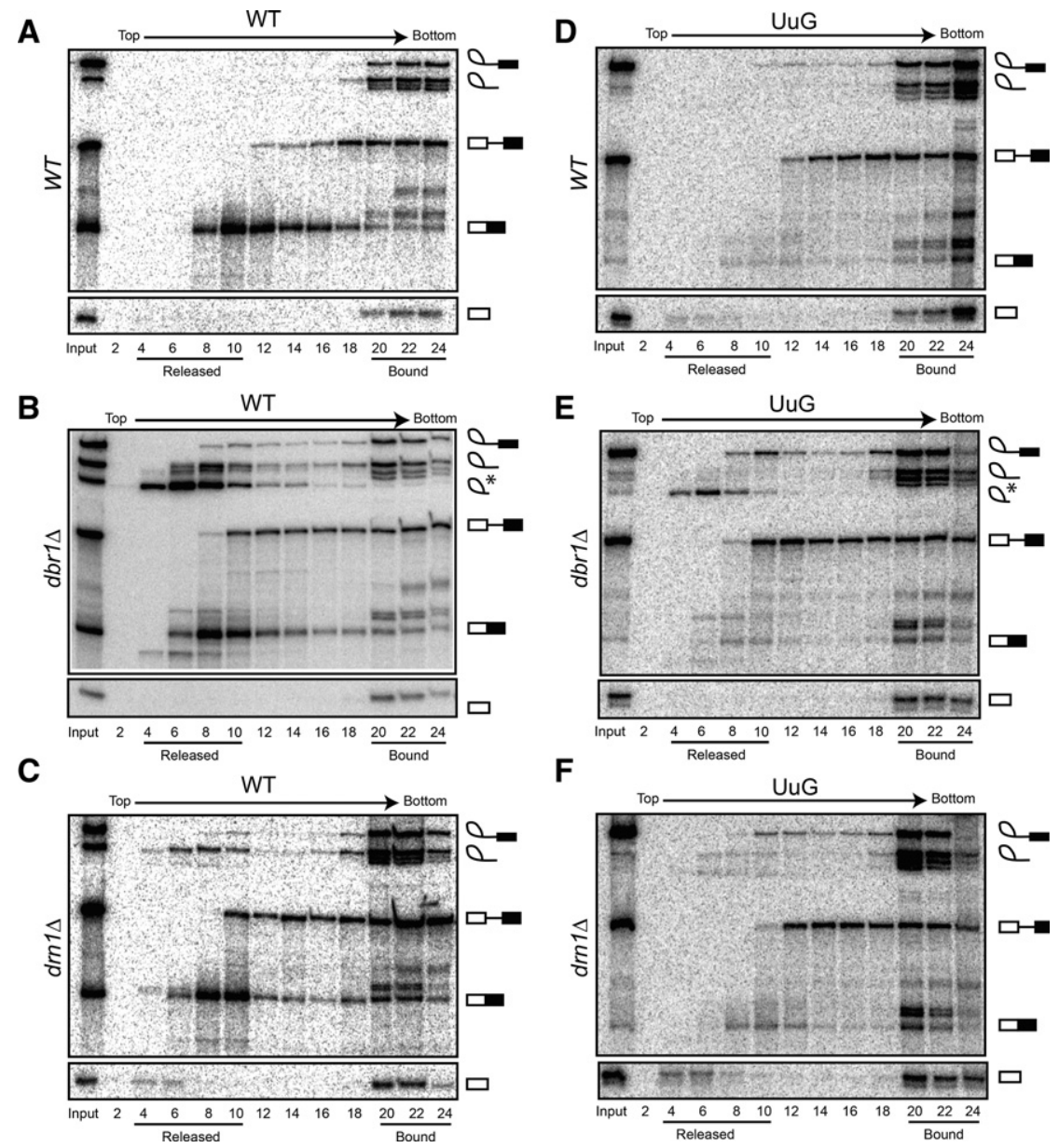

$\mathbf{F}$

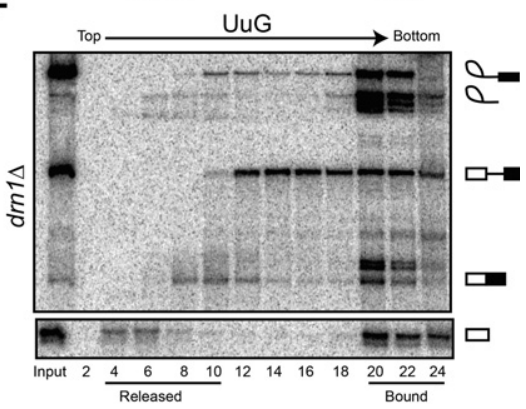

FIGURE 5. Dbr1 and Drn1 modulate branched RNA turnover during in vitro splicing. Splicing of ACT1 pre-mRNA was analyzed by glycerol gradient sedimentation. RNA in even-numbered fractions collected from the top ("released") to the bottom ("bound") of the gradient was analyzed on denaturing polyacrylamide gels. Positions of lariat-intermediate, lariat-intron, a faster-migrating intron form (marked with an asterisk, possibly a lariat lacking a tail), pre-mRNA, spliced mRNA, and $5^{\prime}$-exon are shown for each panel. Splicing of a WT ACT1 pre-mRNA was analyzed in WT $(A), d b r 1 \Delta(B)$, and $d r n 1 \Delta(C)$ extracts. Splicing of WT ACT1 pre-mRNA in $d b r 1 \Delta$ and $d r n 1 \Delta$ extracts causes accumulation of branched intermediates in released fractions $(B, C$, fractions 4-10). A faster-migrating intron (i.e., a lariat without a tail, marked with an asterisk) migrates just below lariat-intron ( $B$, top panel, fractions $4-10)$. Splicing of WT pre-mRNA in $d r n 1 \Delta$ extract causes modest accumulation of $5^{\prime}$-exon in released fractions $(C$, bottom panel, fractions 4-6). Splicing of a pre-mRNA with a $3^{\prime}$-splice site mutation (UAG to UuG) was analyzed in WT $(D), d b r 1 \Delta(E)$, and $d r n 1 \Delta(F)$ extracts. Splicing of UuG substrates in $d r n 1 \Delta$ extract enhances accumulation of released $5^{\prime}$-exon relative to WT extract $(F$, bottom panel, fractions 4-6).

possibly enabling more robust detection of specific molecules by crosslinking. Drn1 was crosslinked to the introns of a total of 46 pre-mRNAs. Many of these were ribosomal protein gene pre-mRNAs, suggesting that detection of these RNAs by Drn1 CLIP-seq was strongly correlated with pre-mRNA expression level.

The RPS17B intron was the only intron that robustly crosslinked with both Drn1 and Dbr1 (Fig. 2F). The RPS17B intron (formerly $r p 51 b$ ) has complementary sequences near its $5^{\prime}$-splice site and branch point that base-pair to promote the first step of its splicing (Libri et al. 2000). Base-pairing in the RPS17B intron may inhibit intron release from post- splicing complexes (Martin et al. 2002; Mayas et al. 2010). Thus, the introns most affected by $d r n 1 \Delta$ may inherently antagonize disassembly. In these cases, it is possible that Drn1 promotes efficient turnover of these introns by enhancing Dbr1 activity.

The significance of robust crosslinking by Dbr1 and Drn1 to the U2 snRNA remains to be determined. Analysis of in vitro disassembly of post-catalytic intron lariat spliceosomes (ILSs) by Prp43, Ntr1, and Ntr2 showed that lariat-intron is associated with U2 snRNA (Fourmann et al. 2013). Insofar as Dbr 1 is only able to debranch disassembled post-catalytic lariat-introns (Martin et al. 2002), crosslinking of Dbr1 and Drn1 to U2 snRNA is unexpected but suggests that Dbr1 may be recruited to lariat-intron complexes for lariat-intron turnover prior to or concomitant with their disassembly from post-splicing complexes but is nevertheless unable to access the branchpoint of the lariat-intron. One candidate for mediating this interaction is the Nineteen Complex component Syf1/Ntc90, which is complexed with the ILS (Fourmann et al. 2013) and may mediate an interaction with Drn1 and Dbr1 (Fig. 2A). However, neither Dbr1 nor Drn1 was identified in mass spectrometry analysis of post-catalytic ILS complexes (Fourmann et al. 2013), suggesting that Dbr1 and Drn1 are recruited at low levels or are not stable components of this complex.

Drn1 significantly improves the RNA debranching activity of Dbr1 in vitro (Fig. 4), and Drn1 appears to modulate Dbr1 activity during splicing in vitro (Fig. 5). In addition, evolutionarily conserved residues in the Drn1 CwfJ domains are required for Drn1 function in vivo (Fig. 2). Other Cwf domains in Drn1 paralogs ( $S$. pombe mug161 and human CWF19L2) are highly homologous to the CwfJ domains in S. cerevisiae Drn1, suggesting that they might also interact with Dbrl to affect RNA debranching.

Drn1-mediated enhancement of Dbr1 debranching appears to involve direct or indirect modulation of catalysis rather than improvement of the affinity of Dbr1 for branched RNA substrates (Fig. 4). Drn1 could promote catalysis of Dbr1 by several mechanisms: Drn1 might directly modulate the Dbr1 active site; Drn1 might indirectly stabilize Dbr1 structure or alleviate an inhibitory interaction between 
domains of Dbr1, thereby enhancing Dbr1 activity; and alternatively, Drn 1 might promote product release by Dbr1. A caveat of this interpretation is that our measurement of Dbr1H86A:RNA complexes may not accurately reflect the affinity of WT Dbr1 for RNA substrates insofar as the His 86 residue is predicted to make direct contact with the scissile phosphate (Khalid et al. 2005). In addition, it is possible that Drn1 does not bind short, branched RNA substrates but is able to bind longer branched RNAs.

Following splicing and release of post-catalytic lariat-introns, Drn1 might improve Dbr1 activity on lariat-introns that are difficult to debranch due to inherent secondary structure that sequesters the branch point. After the completion of splicing, released lariat-intron complexes contain components of the U2 snRNP and components of the Nineteen Complex (Yoshimoto et al. 2009; Fourmann et al. 2013), and these factors may block the access of Dbrl to the branched position of the lariat-intron. Indeed, Dbr1 cannot debranch lariat-introns until they are released from postsplicing complexes by Prp43 (Martin et al. 2002). Loss of Drn1 may therefore reduce the ability of Dbr1 to debranch lariat-introns and lariat-intermediates during or after the disassembly of post-splicing complexes, consistent with the finding that branched RNAs released from the spliceosome accumulate in the absence of Drn1 (Fig. 5).

Drn1 homologs have previously been associated with premRNA splicing in other organisms. In the fission yeast S. pombe, the Drn1 ortholog mug161 is highly expressed during meiosis (Mata et al. 2002), and Mug161p associates with components of the Nineteen complex (Ren et al. 2011). In humans, the Drn1 ortholog CWF19L1 was identified in large-scale proteomic analysis of spliceosomes (Rappsilber et al. 2002). In addition, Drn1 paralogs in S. pombe (cwf19) and metazoans (e.g., human CWF19L2) have C-terminal CwfJ domains, but instead of Dbr1 homology, these paralogs commonly have N-terminal zinc-finger-like or RRM domains (Finn et al. 2009), suggesting a diversification of their functions during splicing. S. pombe Cwf19p associates with the Nineteen Complex (Ohi et al. 2002) and Cwf19L2 was also found in proteomic spliceosomal analysis (Rappsilber et al. 2002), showing that these proteins have retained a splicing-related function.

Drn1 orthologs have an evolutionarily conserved N-terminal domain homologous to the metallophosphoesterase domain of Dbr1 (Fig. 1), but the role of the N-terminal pseudo-metallophosphoesterase domain of Drn1 remains unknown. Evolutionary loss of key catalytic residues (Fig. 1B; Khalid et al. 2005) in Drn1 orthologs suggests that Drn1 does not retain catalytic activity. It is possible that this domain is required for Drn1 to maintain a key contact with the spliceosome and, furthermore, that this contact is the same position at which Dbr1 binds the spliceosome. Consistent with this idea, this domain is sufficient to interact with Ntc90/ Syf1 by yeast two-hybrid analysis (Fig. 2B). Ntc90/Syf1 is a structural component of the Nineteen Complex that recruits the first-step factor Yju2 (Chang et al. 2009), and thus Ntc90/ Syf1 might also recruit Drn1 to the spliceosome by the Drn1 $\mathrm{N}$-terminal domain. Given the interaction of Drn1 with the Ntc90/Syf1 component of the Nineteen Complex, as well as its previous copurification with $S$. cerevisiae Cwc2/Ntc40 (Hazbun et al. 2003) and components of the S. pombe Nineteen Complex (Ohi et al. 2002), we propose that Drn1 is recruited to the spliceosome by the Nineteen Complex. In contrast, we found no interactions between Dbrl and components of the Nineteen Complex (Fig. 2A), suggesting that the interaction with the Nineteen Complex is unique to Drnl. However, insofar as the $\mathrm{N}$-terminal domains of Drn1 and Dbr1 are homologous (Fig. 1) and presumably adopt similar structural folds, the absence of an Dbr1-Ntc90/Syf1 interaction (Fig. 2A, B) is surprising and suggests that the Drn1Ntc90 interaction might be context specific or that the twohybrid assay fails to recapitulate specific aspects of the interaction. Given the evolutionary duplication of the Drn1 protein in $S$. pombe and metazoans (e.g., cwf19 and mug161 in $S$. pombe; CWF19L1 and CWF19L2 in humans) and the absence of a corresponding duplication in Dbrl, we speculate that Drn1 homologs evolved additional roles beyond Dbr1 regulation during splicing.

\section{MATERIALS AND METHODS}

\section{Yeast strains and culturing}

Strains were constructed using standard genetic techniques (Guthrie and Fink 2002). Strains used in this work are listed in Table 1.

\section{Plasmids and oligonucleotides}

Plasmids and oligonucleotides used in this work are listed in Table 2.

\section{Drn1 sequence analysis}

Sequences for Drn 1 and Dbr 1 orthologs were obtained from Uniprot (DBR1_DROME, DBR1_MOUSE, DBR1_HUMAN, DBR1A_ XENLA, DBR1_ARATH, DBR1_CAEEL, DBR1_YEAST, C3H64_ ARATH, C19L1_DROME, C19L1_HUMAN, C19L1_ MOUSE, C19L1_XENLA, C19L1_CAEEL, DRN1_YEAST). Drn1 orthologs and the region of Dbrl homology were identified using the jackhmmer program from the HMMER 3.0 package (Finn et al. 2011). Multiple sequence alignments were visualized using Jalview (Waterhouse et al. 2009).

\section{Yeast two-hybrid assays}

Yeast two-hybrid screens were carried out as previously described (Hazbun et al. 2003), with the exception that ORFs were cloned using custom Gateway (Invitrogen)-compatible Gal4-AD and Gal4$\mathrm{BD}$ fusion vectors. Plasmids containing open reading frames (ORFs; with in-frame stop codons) were obtained from the Harvard ORF collection ( $\mathrm{Hu}$ et al. 2007). Plates were incubated for $7 \mathrm{~d}$ at $30^{\circ} \mathrm{C}$ prior to photographing. 
TABLE 1. Yeast and E. coli strains

\begin{tabular}{|c|c|c|c|}
\hline ID & Description & Genotype & Reference \\
\hline YJH103 & $d b r 1 \Delta$ & 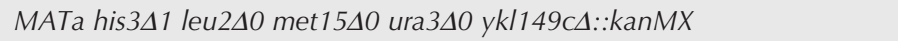 & Open Biosystems \\
\hline YJH105 & $d r n 1 \Delta$ & 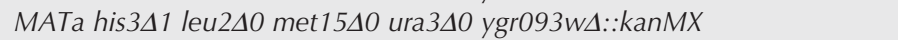 & Open Biosystems \\
\hline YJH107 & Drn1-TAP & 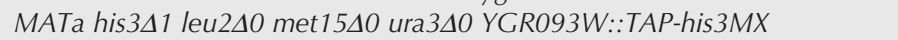 & Open Biosystems \\
\hline YJH109 & $d b r 1 \Delta d r n 1 \Delta$ & 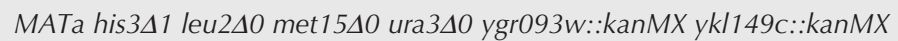 & \\
\hline YJH2O0 & Dbr1-TAP & 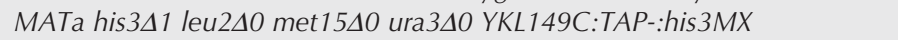 & Open Biosystems \\
\hline YJH266 & BY4743 & 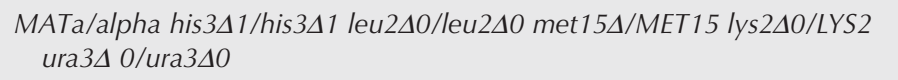 & Open Biosystems \\
\hline $\mathrm{YJH} 267$ & $\begin{array}{l}\text { YGR093W homozygous } \\
\text { deletion }\end{array}$ & 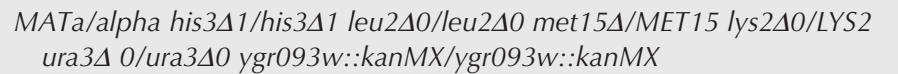 & Open Biosystems \\
\hline YJH434 & $B / 2168$ & MATa pep4-3 prb1-1122 prc1-407 leu2 trp1 ura3-52 & \\
\hline YJH435 & BJ2168 drn14 & MATa pep4-3 prb1-1122 prc1-407 leu2 trp1 ura3-52 drn14::hphMX & \\
\hline YJH538 & $B / 2168 d b r 1 \Delta$ & MATa pep4-3 prb1-1122 prc1-407 leu2 trp1 ura3-52 dbr14::natMX & \\
\hline YJH578 & BJ2168drn1 $\Delta$ Dbr1-Flag & $\begin{array}{l}\text { MATa pep4-3 prb1-1122 prc1-407 leu2 trp1 ura3-52 drn14::hphMX } \\
\text { DBR1::3xFlag }\end{array}$ & $\begin{array}{l}\text { DBR1-Flag tagged with } \\
\text { pZM467 }\end{array}$ \\
\hline YJH580 & BJ2168 Dbr1-Flag & MATa pep4-3 prb1-1122 prc1-407 leu2 trp1 ura3-52 DBR1::3xFlag & \\
\hline
\end{tabular}

\section{Protein expression and purification}

The ORF for S. cerevisiae Dbr1 was cloned into pET-16b (Novagen) creating an N-terminal 10xHis fusion. The Dbr1-H86A mutant was created using the Quickchange reaction (Agilent). The Drn1 ORF was obtained from the Harvard ORF Collection (Hu et al. 2007). The ORF was moved to pDONR221 by BP recombination and then moved to pET-53-DEST by LR recombination creating an N-terminal 6xHis fusion. Dbr1 and Drn1 expression constructs were transformed into BL21 (DE3) RIPL expression cells (Agilent). Cultures were grown to an $\mathrm{OD}_{600}$ of $\sim 0.6$ at $37^{\circ} \mathrm{C}$ and chilled for $30 \mathrm{~min}$ on ice. Ethanol was added to $2 \%$, and expression was induced with $0.4 \mathrm{mM}$ IPTG. Cultures were shaken $16 \mathrm{~h}$ at $17^{\circ} \mathrm{C}$, and cells were harvested by centrifugation. Cells were lysed in Buffer A $(50 \mathrm{mM}$ Tris- $\mathrm{HCl}$ at $\mathrm{pH} 7.5,250 \mathrm{mM} \mathrm{NaCl}, 10 \%$ sucrose) with $0.1 \mathrm{mg} / \mathrm{mL}$ lysozyme at $4^{\circ} \mathrm{C}$ and clarified by centrifugation. Cleared lysates were applied to nickel resin (Qiagen), washed with Buffer E (50 $\mathrm{mM}$ Tris- $\mathrm{HCl}$ at $\mathrm{pH} 7.5,10 \%$ glycerol, $250 \mathrm{mM} \mathrm{NaCl}$ ), and eluted with Buffer $\mathrm{E}+300 \mathrm{mM}$ imidzaole. Peak fractions were pooled and further purified by cation exchange chromatography (Mono S; GE Life Sciences) on a linear gradient of Buffer D (50 mM Tris$\mathrm{HCl}$ at $\mathrm{pH} 7.5,10 \%$ glycerol, $5 \mathrm{mM}$ DTT, 1 mM EDTA at $\mathrm{pH}$ 8.0) from $100 \mathrm{mM}$ to $500 \mathrm{mM} \mathrm{NaCl}$. Proteins typically eluted at 250 $\mathrm{mM} \mathrm{NaCl}$. Peak fractions were pooled and snap-frozen. Protein concentrations were calculated by Bradford assay.

\section{Synthesis of branched RNA oligonucleotides}

Branched RNA compounds were synthesized on a glass solid support, using modifications of published procedures (Braich and Damha 1997; Damha and Braich 1998) and branch point adenosine synthons that permit stepwise installation of the $5^{\prime}-$, $3^{\prime}$-, or $2^{\prime}$-segments (Katolik et al. 2014). Newly synthesized RNA molecules were purified by HPLC and size-exclusion chromatography. The identity of the synthetic branched compounds was verified by mass spectrometry and debranching assays.

\section{Debranching assays}

Purified Dbr1 and Drn1 proteins were incubated with 5 -end-labeled branched RNA substrates in buffer (50 mM MOPS at pH 7.0, $10 \mathrm{mM}$
$\mathrm{MnCl}_{2}$ and $\left.150 \mathrm{mMNaCl}\right)$ at $22^{\circ} \mathrm{C}$. Dbrl was assayed using the concentrations indicated ( 6.25 or $25 \mathrm{nM} \mathrm{Dbr} 1,1 \mathrm{nM} \mathrm{RNA})$ in the presence or absence of Drn1. Time points were removed and quenched in stop dye $(0.1 \%$ bromophenol blue, $0.1 \%$ xylene cyanol, $95 \%$ formamide, $25 \mathrm{mM}$ EDTA at $\mathrm{pH}$ 8.0). Products were separated on $20 \%$ denaturing polyacrylamide gels and quantitated by phosphorimaging.

TABLE 2. Plasmids

\begin{tabular}{|c|c|c|}
\hline ID & Description & Source \\
\hline BJH236 & pDEST-AD & \\
\hline BJH237 & pDEST-BD & \\
\hline BJH239 & pDEST-AD-DRN1 & \\
\hline $\mathrm{BJH} 240$ & pDEST-BD-DRN1 & \\
\hline ВJH249 & pDEST-AD-DBR1 & \\
\hline ВJH250 & pDEST-BD-DBR1 & \\
\hline BJH253 & pDEST-AD-SYF1 & \\
\hline BJH254 & pDEST-BD-SYF1 & \\
\hline BJH256 & pDEST-AD-MEC3 & \\
\hline BJH257 & pDEST-BD-RAD17 & \\
\hline BJH342 & pRS415GPD-DRN1 & \\
\hline BJH343 & pRS415GPD-DRN1-D17A & \\
\hline ВJH344 & pRS415GPD-DRN1-D34A & \\
\hline BJH345 & pRS415GPD-DRN1-C269A & \\
\hline BJH346 & pRS415GPD-DRN1-C272A & \\
\hline BJH347 & pRS415GPD-DRN1-H311A & \\
\hline $\mathrm{BJH} 348$ & pRS415GPD-DRN1-H319A & \\
\hline BJH349 & pRS415GPD-DRN1-H361A & \\
\hline ВJH350 & pRS415GPD-DRN1-H368A & \\
\hline BJH351 & pRS415GPD-DRN1-R459A & \\
\hline BJH352 & pRS415GPD-DRN1-W474A & \\
\hline BJH353 & pRS415GPD-DRN1-C479A & \\
\hline ВJH354 & pRS415GPD-DRN1-E486A & \\
\hline ВJH355 & pRS415GPD-DRN1-D501A & \\
\hline BJH588 & JPS149 (ACT1 WT) & (Mayas et al. 2010) \\
\hline BJH602 & JPS149 UuG & (Mayas et al. 2010) \\
\hline BJH502 & pET16b-Dbr1 & \\
\hline BJH152 & pET-16b-Dbr1-H86A & \\
\hline BJH168 & pET16b-Drn1 & \\
\hline BJH488 & pZM467 (3x-Flag vector) & $\begin{array}{c}\text { (Moqtaderi and } \\
\text { Struhl 2008) }\end{array}$ \\
\hline
\end{tabular}




\section{Filter binding assays}

Binding reactions were assembled with recombinant Dbr1, Dbr1-

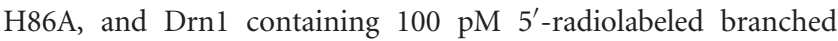
RNA substrate (50 mM MOPS at pH 7.0, $100 \mathrm{mM} \mathrm{NaCl}, 10 \mathrm{mM}$ $\mathrm{MnCl}_{2}$ ). Reactions were incubated for $30 \mathrm{~min}$ at $22^{\circ} \mathrm{C}$ and filtered through sandwiched nitrocellulose (Protran, Whatman) and nylon (Hybond N+, GE Life Sciences) membranes. Bound complexes were washed twice with $200 \mu \mathrm{L}$ binding buffer. Membranes were dried and exposed to PhosphoImager screens to determine the fraction of RNA in bound to the nitrocellulose membrane. Curve fitting was performed in Graphpad Prism.

\section{Dbr1 and Drn1 interaction analysis}

Immunoprecipitation experiments were carried out using anti-Flag M2 resin (Sigma) and splicing extracts. Prewashed resin was resuspended in $450 \mu \mathrm{L}$ of IPP150 buffer and $50 \mu \mathrm{L}$ of spicing extract prepared from the WT, Dbr1-Flag strain, or Dbr1-Flag drn1 1 strain. After removal of an input aliquot, reactions were incubated for 1 $\mathrm{h}$ at $4^{\circ} \mathrm{C}$ and washed three times with $500 \mu \mathrm{L}$ of IPP 150 buffer. After the final wash, the resin was resuspended in $25 \mu \mathrm{L}$ of $1 \times$ SDS-PAGE loading dye. All samples were incubated for $5 \mathrm{~min}$ at $95^{\circ} \mathrm{C}$ before loading on a precast NuPAGE $10 \%$ Bis-Tris gel (Novex, Life Technologies) and then blotted to nitrocellulose. Membranes were probed with polyclonal antisera against Drn1 $(1: 15,000)$ or anti-Flag antibody $(1: 15,000)$. HRP-conjugated secondary antibodies were used with ECL for visualization.

\section{Glycerol gradient analysis of in vitro splicing}

Splicing extracts were prepared as previously described (Stevens and Abelson 2002), except that cells were disrupted in a cryogenic ball mill (Retsch MM401) five times for $3 \mathrm{~min}$ at $10 \mathrm{~Hz}$ (Mayas et al. 2006). Splicing substrates were generated by T7 RNA polymerase transcription of an ACT1 pre-mRNA lacking a cryptic branch site (Vijayraghavan et al. 1986) in the presence of $\left[a-{ }^{32} \mathrm{P}\right]$ UTP. Point mutations were introduced by QuikChange mutagenesis and confirmed by Sanger sequencing. Splicing reactions $\left(60 \mathrm{mM} \mathrm{KH}_{2} \mathrm{PO}_{4}\right.$ at pH 7.0, 2 mM ATP, $3 \mathrm{mM} \mathrm{MgCl}_{2}$, 3\% PEG 8000, $1 \mathrm{mM}$ spermidine; $100 \mu \mathrm{L}$ total) were incubated for $20 \mathrm{~min}$ at $22^{\circ} \mathrm{C}$ and stopped by cooling on ice. After removal of an input aliquot, reactions were

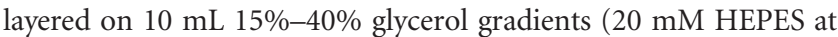
$\mathrm{pH} 6.5,100 \mathrm{mM} \mathrm{KCl}, 2 \mathrm{mM} \mathrm{MgCl}_{2}$ ) and sedimented at 35,000 RPM for $14 \mathrm{~h}$ at $4^{\circ} \mathrm{C}$ in a Beckman SW 41 rotor. Fractions $(400$ $\mu \mathrm{L}$ ) were manually collected from the top of the gradients, phenol:chloroform extracted, and ethanol precipitated. Even-numbered fractions were analyzed on 6\% polyacrylamide (29:1) sequencing gels with $7 \mathrm{M}$ urea and $1 \times \mathrm{TBE}$; the faster-migrating intron form was not well resolved in 19:1 polyacrylamide. Dried gels were exposed to PhosphorImager screens for quantitation.

\section{Microarray analysis}

Microarray analysis was performed as previously described (Hiley et al. 2005). Briefly, total RNA from diploid BY4743 and derivative $d r n 1 \Delta / d r n 1 \Delta$ strains (Open Biosystems) was labeled using a direct RNA labeling kit (Ulysis labeling kit, Invitrogen). Labeled RNA was hybridized to microarrays (Agilent Technologies; $4 \times 44 \mathrm{k}$ format) containing probes that tile across approximately 400 yeast noncoding RNAs (Hiley et al. 2005). Two independent RNA preparations from each strain were included in a dye-swap experiment to yield four independent cohybridizations. Following hybridization, arrays were scanned and intensity data were processed using the marray package from Bioconductor (Gentleman et al. 2004). Data for array hybridizations are available from the NCBI Gene Expression Omnibus (Barrett et al. 2010) under accession no. GSE15418.

\section{Northern blotting}

Total RNA was isolated using acid phenol, resolved on 6\% denaturing acrylamide gels containing $1 \times \mathrm{TBE}$ and $7 \mathrm{M}$ urea, and electroblotted to HyBond $\mathrm{N}+$ membranes (GE Life Sciences). Molecular weights were estimated by staining of a lane containing RNA Century-Plus (Ambion) excised prior to blotting. Double-stranded DNA probes complementary to exon or intron regions were PCR amplified and labeled with $\left[a-{ }^{32} \mathrm{P}\right]$ dCTP using Ready-To-Go labeling beads (GE Life Sciences). Probes were hybridized to membranes in UltraHyb (Ambion) overnight at $42^{\circ} \mathrm{C}$, washed twice with buffer ( $2 \times$ SSC, $0.1 \%$ SDS) at room temperature, and exposed to PhosphorImager screens (GE Life Sciences).

\section{CLIP-seq of Dbr1 and Drn1}

CLIP-seq experiments were carried out as previously described ( $\mathrm{Li}$ et al. 2013). Briefly, strains with TAP-tagged Dbr1 and Drn1 proteins (Ghaemmaghami et al. 2003) were grown to an $\mathrm{OD}_{600}$ of 2.0 in YEPD, crosslinked with $800 \mathrm{~mJ} / \mathrm{cm}^{2}$ of $254 \mathrm{~nm}$ light for 10 min, and harvested by centrifugation. Cells were cryogenically milled (Spex Freezer/Mill) to extract RNA-protein complexes, followed by subsequent ribonuclease trimming, $5^{\prime}$ phosphorylation with $\left[\gamma^{-}{ }^{32} \mathrm{P}\right]$ ATP, and adaptor ligation. Crosslinked RNA-protein complexes were resolved by SDS-PAGE, and labeled RNAs in the gel were visualized by phosphorimaging. Complexes migrating above the band corresponding to the protein molecular weight were excised and recovered by crushing the gel in buffer $(0.3 \mathrm{M}$ $\mathrm{NaCl}, 10 \mathrm{mM}$ EDTA at $\mathrm{pH} 8.0$ ), followed by precipitation. Proteins were digested by Proteinase K, and RNAs were converted to libraries by reverse transcription and PCR with indexed primers. Libraries were sequenced on an Illumina GA IIx or HiSeq 2000 platforms and aligned to the S. cerevisiae genome (sacCer1 in the UCSC genome browser) using bowtie2 (Langmead and Salzberg 2012). We obtained a total of 2,216,092 reads ( $82 \%$ mappable) from the Dbr1 library and 2,044,592 reads ( $81 \%$ mappable) from the Drn1 library. Of the aligned reads, $30 \%$ mapped to annotated snRNAs (U1, U2 $\mathrm{U} 4, \mathrm{U} 5$, and U6). In addition, $1 \%$ of the reads mapped to annotated pre-mRNAs and introns. The majority of the remaining reads were derived from ribosomal RNA. Data from CLIP-seq experiments are available from the NCBI Gene Expression Omnibus (Barrett et al. 2010) under accession number GSE44959.

\section{ACKNOWLEDGMENTS}

We thank B. Schwer, C. Query, and J. Staley for strains, plasmids, and helpful discussions. We thank R. Davis and T. Blumenthal for discussions and comments on the manuscript. This study was funded in part by the NIH (P41 GM103533). S.F. is an investigator of the Howard Hughes Medical Institute. J.R.H. is funded by a Damon 
Runyon-Rachleff Innovator Award and a Research Scholar Grant from the American Cancer Society. M.J.D. was funded by a grant from the Natural Science and Engineering Council of Canada (Discovery Grant). R.Z. was supported by a grant from the NIH (R01 GM080334).

Received January 30, 2014; accepted April 16, 2014.

\section{REFERENCES}

Alberti S, Gitler AD, Lindquist S. 2007. A suite of Gateway cloning vectors for high-throughput genetic analysis in Saccharomyces cerevisiae. Yeast 24: 913-919.

Arenas J, Hurwitz J. 1987. Purification of a RNA debranching activity from HeLa cells. J Biol Chem 262: 4274-4279.

Barrett T, Troup DB, Wilhite SE, Ledoux P, Evangelista C, Kim IF, Tomashevsky M, Marshall KA, Phillippy KH, Sherman PM, et al. 2010. NCBI GEO: archive for functional genomics data sets: 10 years on. Nucleic Acids Res 39: D1005-D1010.

Braich RS, Damha MJ. 1997. Regiospecific solid-phase synthesis of branched oligonucleotides: effect of vicinal $2^{\prime}, 5^{\prime}-\left(\right.$ or $2^{\prime}, 3^{\prime}-$ ) and $3^{\prime}, 5^{\prime}$-phosphodiester linkages on the formation of hairpin DNA. Bioconjug Chem 8: 370-377.

Chang KJ, Chen HC, Cheng SC. 2009. Ntc90 is required for recruiting first step factor Yju2 but not for spliceosome activation. RNA 15: 1729-1739.

Chen W, Shulha HP, Ashar-Patel A, Yan J, Green KM, Query CC, Rhind N, Weng Z, Moore MJ. 2014. Endogenous U2.U5.U6 snRNA complexes in $S$. pombe are intron lariat spliceosomes. $R N A$ 20: $308-320$.

Damha MJ, Braich RS. 1998. Synthesis of a branched DNA/RNA chimera similar to the msDNA molecule of Myxococcus xanthus. Tetrahedron Lett 39: 3907-3910.

Dix I, Russell C, Yehuda SB, Kupiec M, Beggs JD. 1999. The identification and characterization of a novel splicing protein, Isylp, of Saccharomyces cerevisiae. RNA 5: 360-368.

Finn RD, Mistry J, Tate J, Coggill P, Heger A, Pollington JE, Gavin OL, Gunasekaran P, Ceric G, Forslund K, et al. 2009. The Pfam protein families database. Nucleic Acids Res 38: D211-D222.

Finn RD, Clements J, Eddy SR. 2011. HMMER web server: interactive sequence similarity searching. Nucleic Acids Res 39: W29-W37.

Fourmann J-B, Schmitzová J, Christian H, Urlaub H, Ficner R, Boon KL, Fabrizio P, Lührmann R. 2013. Dissection of the factor requirements for spliceosome disassembly and the elucidation of its dissociation products using a purified splicing system. Genes Dev 27: 413-428.

Gavin A-C, Aloy P, Grandi P, Krause R, Boesche M, Marzioch M, Rau C, Jensen LJ, Bastuck S, Dümpelfeld B, et al. 2006. Proteome survey reveals modularity of the yeast cell machinery. Nature 440: 631-636.

Gentleman RC, Carey VJ, Bates DM, Bolstad B, Dettling M, Dudoit S, Ellis B, Gautier L, Ge Y, Gentry J, et al. 2004. Bioconductor: open software development for computational biology and bioinformatics. Genome Biol 5: R80.

Ghaemmaghami S, Huh WK, Bower K, Howson RW, Belle A, Dephoure N, O'Shea EK, Weissman JS. 2003. Global analysis of protein expression in yeast. Nature 425: 737-741.

Grainger RJ, Beggs JD. 2005. Prp8 protein: at the heart of the spliceosome. RNA 11: 533-557.

Guthrie C, Fink GR. 2002. Guide to yeast genetics and molecular and cell biology, Vol. 351. Academic Press, San Diego, CA.

Hazbun TR, Malmström L, Anderson S, Graczyk BJ, Fox B, Riffle M, Sundin BA, Aranda JD, McDonald WH, Chiu C-H, et al. 2003. Assigning function to yeast proteins by integration of technologies. Mol Cell 12: 1353-1365.

Hesselberth JR. 2013. Lives that introns lead after splicing. WIREs RNA 4: 677-691.
Hiley SL, Babak T, Hughes TR. 2005. Global analysis of yeast RNA processing identifies new targets of RNase III and uncovers a link between tRNA $5^{\prime}$ end processing and tRNA splicing. Nucleic Acids Res 33: 3048-3056.

Hilleren PJ, Parker R. 2003. Cytoplasmic degradation of splice-defective pre-mRNAs and intermediates. Mol Cell 12: 1453-1465.

Hu Y, Rolfs A, Bhullar B, Murthy TVS, Zhu C, Berger MF, Camargo AA, Kelley F, McCarron S, Jepson D, et al. 2007. Approaching a complete repository of sequence-verified protein-encoding clones for Saccharomyces cerevisiae. Genome Res 17: 536-543.

Jacquier A, Rosbash M. 1986. RNA splicing and intron turnover are greatly diminished by a mutant yeast branch point. Proc Natl Acad Sci 83: 5835-5839.

Kataoka N, Dobashi I, Hagiwara M, Ohno M. 2013. hDbrl is a nucleocytoplasmic shuttling protein with a protein phosphatase-like motif essential for debranching activity. Sci Rep 3: 1090.

Katolik A, Johnsson R, Montemayor E, Lackey JG, Hart PJ, Damha MJ. 2014. Regiospecific solid-phase synthesis of branched oligoribonucleotides that mimic intronic lariat RNA intermediates. $\mathrm{J} \mathrm{Org}$ Chem 79: 963-975.

Khalid MF, Damha MJ, Shuman S, Schwer B. 2005. Structure-function analysis of yeast RNA debranching enzyme (Dbr1), a manganese-dependent phosphodiesterase. Nucleic Acids Res 33: 63496360.

Krämer A, Keller W. 1985. Purification of a protein required for the splicing of pre-mRNA and its separation from the lariat debranching enzyme. EMBO J 4: 3571-3581.

Langmead B, Salzberg SL. 2012. Fast gapped-read alignment with Bowtie 2. Nat Methods 9: 357-359.

Li X, Zhang W, Xu T, Ramsey J, Zhang L, Hill R, Hansen KC, Hesselberth JR, Zhao R. 2013. Comprehensive in vivo RNA-binding site analyses reveal a role of Prp8 in spliceosomal assembly. Nucleic Acids Res 41: 3805-3818.

Libri D, Lescure A, Rosbash M. 2000. Splicing enhancement in the yeast rp51b intron. RNA 6: 352-368.

Liu L, Query CC, Konarska MM. 2007. Opposing classes of prp8 alleles modulate the transition between the catalytic steps of pre-mRNA splicing. Nat Struct Mol Biol 14: 519-526.

Martin A, Schneider S, Schwer B. 2002. Prp43 is an essential RNA-dependent ATPase required for release of lariat-intron from the spliceosome. J Biol Chem 277: 17743-17750.

Mata J, Lyne R, Burns G, Bähler J. 2002. The transcriptional program of meiosis and sporulation in fission yeast. Nat Genet 32: 143-147.

Mayas RM, Maita H, Staley JP. 2006. Exon ligation is proofread by the DExD/H-box ATPase Prp22p. Nat Struct Mol Biol 13: 482-490.

Mayas RM, Maita H, Semlow DR, Staley JP. 2010. Spliceosome discards intermediates via the DEAH box ATPase Prp43p. Proc Natl Acad Sci 107: 10020-10025.

Moqtaderi Z, Struhl K. 2008. Expanding the repertoire of plasmids for PCR-mediated epitope tagging in yeast. Yeast 25: 287-292.

Nam K, Hudson RH, Chapman KB, Ganeshan K, Damha MJ, Boeke JD. 1994. Yeast lariat debranching enzyme. Substrate and sequence specificity. J Biol Chem 269: 20613-20621.

Ohi MD, Link AJ, Ren L, Jennings JL, McDonald WH, Gould KL. 2002. Proteomics analysis reveals stable multiprotein complexes in both fission and budding yeasts containing Myb-related Cdc5p/Ceflp, novel pre-mRNA splicing factors, and snRNAs. Mol Cell Biol 22: 2011-2024.

Rappsilber J, Ryder U, Lamond AI, Mann M. 2002. Large-scale proteomic analysis of the human spliceosome. Genome Res 12: 12311245.

Ren L, McLean JR, Hazbun TR, Fields S, Vander Kooi C, Ohi MD, Gould KL. 2011. Systematic two-hybrid and comparative proteomic analyses reveal novel yeast pre-mRNA splicing factors connected to Prp19. PLoS One 6: e16719.

Ruby JG, Jan CH, Bartel DP. 2007. Intronic microRNA precursors that bypass Drosha processing. Nature 448: 83-86.

Siepel A, Bejerano G, Pedersen JS, Hinrichs AS, Hou M, Rosenbloom K, Clawson H, Spieth J, Hillier LW, Richards S, et al. 2005. 


\section{Garrey et al.}

Evolutionarily conserved elements in vertebrate, insect, worm, and yeast genomes. Genome Res 15: 1034-1050.

Stark C, Su T-C, Breitkreutz A, Lourenco P, Dahabieh M, Breitkreutz B-J, Tyers M, Sadowski I. 2010. PhosphoGRID: a database of experimentally verified in vivo protein phosphorylation sites from the budding yeast Saccharomyces cerevisiae. Database (Oxford) 2010: bap026.

Stevens SW, Abelson J. 2002. Yeast pre-mRNA splicing: methods, mechanisms, and machinery. Methods Enzymol 351: 200-220.

Tanaka N, Aronova A, Schwer B. 2007. Ntr1 activates the Prp43 helicase to trigger release of lariat-intron from the spliceosome. Genes Dev 21: 2312-2325.

Tsai R-T, Tseng C-K, Lee P-J, Chen H-C, Fu R-H, Chang K-J, Yeh F-L, Cheng S-C. 2007. Dynamic interactions of Ntr1-Ntr2 with Prp43 and with U5 govern the recruitment of Prp43 to mediate spliceosome disassembly. Mol Cell Biol 27: 8027-8037.

Vijayraghavan U, Parker R, Tamm J, Iimura Y, Rossi J, Abelson J, Guthrie C. 1986. Mutations in conserved intron sequences affect multiple steps in the yeast splicing pathway, particularly assembly of the spliceosome. EMBO J 5: 1683-1695.

Waterhouse AM, Procter JB, Martin DMA, Clamp M, Barton GJ. 2009. Jalview version 2: a multiple sequence alignment editor and analysis workbench. Bioinformatics 25: 1189-1191.

Yoshimoto R, Kataoka N, Okawa K, Ohno M. 2009. Isolation and characterization of post-splicing lariat-intron complexes. Nucleic Acids Res 37: 891-902.

Zhang C, Darnell RB. 2011. Mapping in vivo protein-RNA interactions at single-nucleotide resolution from HITS-CLIP data. Nat Biotechnol 29: 607-614. 

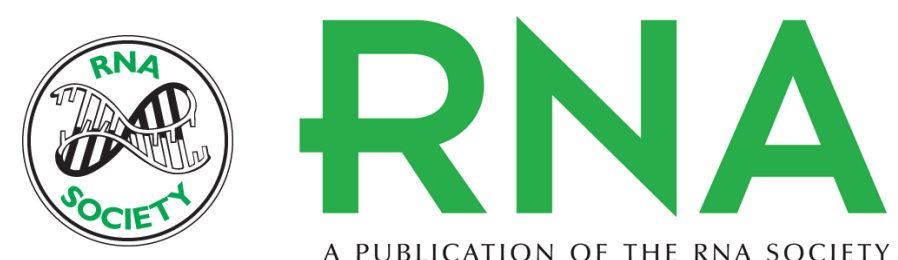

A PUBLICATION OF THE RNA SOCIETY

\section{A homolog of lariat-debranching enzyme modulates turnover of branched RNA}

Stephen M. Garrey, Adam Katolik, Mantas Prekeris, et al.

RNA 2014 20: 1337-1348 originally published online June 11, 2014

Access the most recent version at doi:10.1261/rna.044602.114

\section{References This article cites 48 articles, 17 of which can be accessed free at: http://rnajournal.cshlp.org/content/20/8/1337.full.html\#ref-list-1 \\ Creative This article is distributed exclusively by the RNA Society for the first 12 months after the Commons full-issue publication date (see http://rnajournal.cshlp.org/site/misc/terms.xhtml). After 12 License months, it is available under a Creative Commons License (Attribution-NonCommercial 4.0 International), as described at http://creativecommons.org/licenses/by-nc/4.0/.}

Email Alerting Receive free email alerts when new articles cite this article - sign up in the box at the Service top right corner of the article or click here. 